\title{
METHODOLOGY AND CURRENT STATUS OF THE \\ PREDICTION OF THE DRASTIC RETREAT OF COLUMBIA \\ GLACIER, ALASKA
}

(Abstract only)

by

\author{
M. F. Meier, L. A. Rasmussen and W. G. Sikonia \\ (U.S. Geological Survey, Tacoma, Washington 98402, U.S.A.)
}

\section{ABSTRACT}

The US Geological Survey was asked to predict the rate of retreat of the terminus of Columbia Glacier, Alaska, which is a large $\left(1100 \mathrm{~km}^{2}\right)$, grounded, iceberg-calving glacier, and to estimate the time distribution of the attendant discharge of icebergs. An extensive field program, using 1 September 1977 through 31 August 1978 as the principal year of study, obtained ice-surface altitudes and velocities, massbalance values and thickness changes, and bed topography estimated from radio echo-sounding for Columbia Glacier. These data were subjected to complex one- and two-dimensional adjustment programs to assure consistency with the equations of continuity and glacier flow.

$A$ one-dimensional numerical model based on the continuity equation was used to make the initial prediction, issued in June 1980. The continuity equation is applied to the lower $14 \mathrm{~km}$ of the glacier to determine the ice flux to the terminus, and the speed of iceberg calving is taken to be proportional to the average water depth at the terminus. Instead of calculating the dynamics of glacier flow independently, the model requires that a sequence of longitudinal profiles be supplied. Through the calving relationship and other applications of the continuity equation, the model then determines the times at which the glacier assunes each of the supplied profiles. The effect on the predicted rate of retreat caused by the arbitrary nature of the longitudinal profiles is less than the effect of other uncertainties in the data used. A one-dimensional finitedifference dynamic model using the same calving relation gave similar results to those of the continuity model.

A two-dimensional, time-dependent, finite-element computer model was also developed. It describes the dynamics of glacier flow along the centerline of the lower glacier using a calving law that relates calving speed to water discharge and to the height of the ice column unsupported by water buoyancy.

The retreat predicted by the continuity model slowly accelerates from the initial observed rate of $45 \mathrm{~m} \mathrm{a}^{-1}$ until January $1983 \pm 10$ months, when the retreat rate increases to about $4 \mathrm{~km} \mathrm{a}^{-1}$. At some time between October 1983 and July 1986, the terminus is expected to retreat $9.5 \mathrm{~km}$. An annual icebergcalving flux of about $10 \mathrm{~km}^{3} \mathrm{a}^{-1}$, which is 6 to 8 times the 1978 flux, is expected to occur in 1984; daily or weekly peaks will be much higher. The twodimensional dynamic model gives similar results, suggesting that retreat will accelerate in 1983, and that a maximum calving flux will be attained in 1984 (see Fig.1).

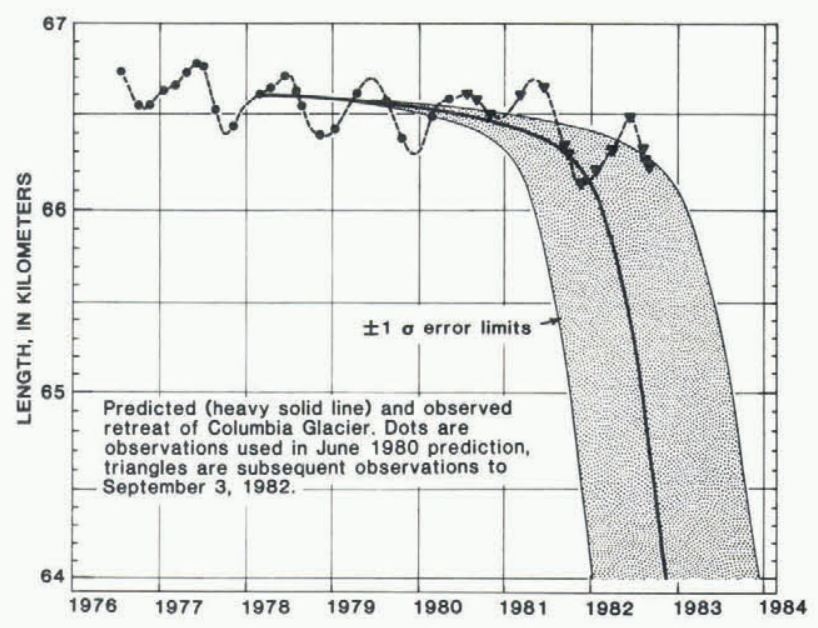

Fig.1. Predicted retreat based on the continuity equation model, and observed retreat to 3 September 1982.

In the summer of 1980 , calving was much less than that observed in previous years, probably due to low amounts of run-off, the fact that the stream discharged in an area of shallow water, and an unusually positive mass-balance year. Thus, the observed retreat is slower than that predicted. However, on 3 September 1982, the observed retreat was within the bounds of error of the original prediction. 